\title{
Efeitos de diferentes doses de hiclato de doxiciclina nos parâmetros hematológicos de cães com erliquiose
}

\section{Effects of different doses of doxycycline hyclate on haematological parameters of dogs with ehrlichiosis}

\author{
Mariana Cristina Hoeppner Rondelli ${ }^{1}$, Reinaldo Juan Garrido Palacios Junior ${ }^{2}$, Igor \\ Luiz Salardani Senhorello ${ }^{3}$, Áureo Evangelista Santana ${ }^{4}$, Mirela Tinucci-Costa $^{5}$
}

\section{Resumo}

\begin{abstract}
Este estudo objetivou comparar os efeitos de duas doses de hiclato de doxiciclina sobre a contagem de hemácias, concentração de hemoglobina, hematócrito, contagem de leucócitos e plaquetas de cães com erliquiose. Foram estudados os grupos I, composto por cães saudáveis $(\mathrm{n}=6)$, negativos na sorologia para Ehrlichia canis e Leptospira spp., na PCR em tempo real para E. canis e Anaplasma platys e na semi-nested PCR para Babesia canis; grupos II $(\mathrm{n}=6)$ e III $(\mathrm{n}=6)$, compostos por cães com história clínica sugestiva, sorologia e/ou PCR em tempo real positivas para E. canis, e negativos na pesquisa de anticorpos anti-Leptospira spp., na PCR em tempo real para $A$. platys e na semi-nested PCR para $B$. canis. Os cães doentes foram tratados com hiclato de doxiciclina via oral a cada 12 horas por 30 dias ( $5 \mathrm{mg} / \mathrm{kg}$, grupo II; $10 \mathrm{mg} / \mathrm{kg}$, grupo III). Hemogramas foram feitos antes, decorridos 15 dias e aos 10 dias após o término dos tratamentos. Não houve diferenças entre os grupos nos tempos avaliados quanto às variáveis hemácias, hemoglobina, hematócrito e leucócitos. Observou-se diferença quanto aos trombócitos entre o grupo I e os grupos II e III ( $<<0,0001)$ no início do estudo. Aos 15 dias de tratamento, a média do grupo III foi menor que dos grupos I $(\mathrm{p}=0,008)$ e II $(\mathrm{p}=0,0007)$, indicando persistência da trombocitopenia, ausente no grupo II. Não houve diferença entre os grupos no tempo final, sugerindo que ambos os tratamentos promoveram aumento da contagem de plaquetas em cães naturalmente infectados por E. canis.
\end{abstract}

Palavras-chave: Ehrlichia canis. Hematologia. Plaquetas.

\begin{abstract}
This study aimed to compare the effects of two doses of doxycycline hyclate on red blood cells, hemoglobin, hematocrit, white blood cells and platelets of dogs with ehrlichiosis. Group I, comprised of healthy dogs $(\mathrm{n}=6)$, negative on serology for Ehrlichia canis and Leptospira spp., real time PCR for E. canis and Anaplasma platys, and on semi-nested PCR for Babesia canis; Groups II $(\mathrm{n}=6)$ and III $(\mathrm{n}=6)$, comprised of dogs with suggestive clinical history, positive serology and/or real time PCR for $E$. canis, negative on research for anti-Leptospira spp. antibodies and real time PCR for A. platys, and on semi-nested PCR for $B$. canis were studied. Sick dogs were treated with doxycycline hyclate every 12 hours, by mouth, for 30 days ( $5 \mathrm{mg} / \mathrm{kg}$, group II; $10 \mathrm{mg} / \mathrm{kg}$, group III). Complete blood counts were performed before, after 15 days, and 10 days after period of treatment was complete. No difference between groups at the studied time points were noticed for red blood cells, hemoglobin, haematocrit and white blood cells. Difference was observed for platelets between group I and groups II and III $(p<0.0001)$ at the study onset. After 15 days of treatment, the mean platelet for group III was lower

\footnotetext{
${ }^{1}$ Profa. Dra. do Curso de Graduação em Medicina Veterinária do Instituto Federal de Educação, Ciência e Tecnologia do Sul de Minas Gerais IFSULDEMINAS, campus Muzambinho.Email: marianarondelli@gmail.com.

2 Prof. Me. do Curso de Graduação em Medicina Veterinária da PUC MINAS, Poços de Caldas. Email: reinaldojgpjunior@gmail.com.

${ }^{3}$ Mestrando em Medicina Veterinária pela FCAV/Unesp/Jaboticabal-SP. E-mail: salardani@hotmail.com.

${ }^{4}$ Professor Titular do Departamento de Clínica e Cirurgia Veterinária da FCAV/Unesp/Jaboticabal-SP. E-mail: santana@fcav. unesp.br.

${ }^{5}$ Profa. Dra. do Departamento de Clínica e Cirurgia Veterinária da FCAV/Unesp/Jaboticabal-SP. E-mail: mirelatc@fcav.unesp.br.
} 
than groups I ( $\mathrm{p}=0.008)$ and II $(\mathrm{p}=0.0007)$, indicative of persistent thrombocytopenia, already absent in group II. No difference between groups was noticed at final time point, which suggests that both treatments increased platelets in dogs naturally infected with E. canis.

Keywords: Ehrlichia canis. Hematology. Blood platelets.

\section{Introdução}

A erliquiose monocítica canina é uma doença multissistêmica, provocada pela bactéria gramnegativa Ehrlichia canis, um parasita intracelular obrigatório que tem tropismo por monócitos, macrófagos e trombócitos, apresentando-se na forma de cluster intracitoplasmático, denominado mórula (NEER; HARRUS, 2006). O carrapato marrom do cão (Rhipicephalus sanguineus) é o vetor da doença, por meio da inoculação do parasita pela secreção salivar infectada (MOREIRA et al., 2003; BULLA et al., 2004; DAGNONE et al., 2009).

A avaliação hematológica é essencial na suspeição da infecção por E. canis em cães (HARRUS; WANER, 2011). Na fase aguda da doença, ocorre trombocitopenia de leve a moderada, podendo ou não ser acompanhada de leucopenia e/ou anemia. Já na fase subclínica, a trombocitopenia leve é a única alteração clínica verificada. A fase crônica, por sua vez, é marcada por trombocitopenia severa, que ocorre como parte da pancitopenia característica desta fase (HARRUS; WANER; BARK, 1997; LAPPIN, 2006; NEER; HARRUS, 2006).

As tetraciclinas são os fármacos de escolha no tratamento da erliquiose canina, sendo a doxiciclina e a minociclina as empregadas com maior frequência (NEER et al., 2002; NEER; HARRUS, 2006). Estes antimicrobianos são bacteriostáticos lipossolúveis, prontamente absorvidos e atingem concentrações séricas e intracelulares satisfatórias, fatores importantes na eliminação de parasitas intracelulares (SPINOSA, 2002). Em casos não complicados, a melhora clínica ocorre de 24 a 48 horas após o início do tratamento com tetraciclinas (NEER et al., 2002). Embora o Grupo de Estudos em Doenças Infecciosas do Colégio Americano de Medicina Veterinária aconselhe a dose de doxiciclina de $10 \mathrm{mg} / \mathrm{kg}$, via oral, a cada 24 horas por 28 dias para o tratamento da erliquiose monocítica canina (NEER et al., 2002), na rotina clínica do Hospital Veterinário "Governador Laudo Natel", da FCAV/Unesp, Jaboticabal-SP, o protocolo terapêutico adotado era o adaptado de Troy e Forrester (1990) e utilizado por Munhoz et al. (2012). Neste protocolo, utilizavam-se $5 \mathrm{mg} /$ $\mathrm{kg}$ de doxiciclina, via oral, a cada 12 horas por 28 dias. Entretanto, as mais rápidas recuperações dos cães infectados são por nós observadas quando se emprega a doxiciclina na dose de $10 \mathrm{mg} / \mathrm{kg}$ a cada 12 horas, por um período mínimo de 30 dias.

Assim, o estudo em tela objetivou comparar os efeitos de duas diferentes doses de hiclato de doxiciclina sobre a contagem de hemácias, concentração de hemoglobina, hematócrito, contagem de leucócitos e de plaquetas de cães naturalmente infectados por Ehrlichia canis.

\section{Material e métodos}

O projeto foi aprovado pela Comissão de Ética no Uso de Animais (CEUA) local sob o protocolo ${ }^{\circ}$ 023938/14. Os cães foram incluídos no estudo após o consentimento livre e esclarecido, por escrito, pelos proprietários.

\section{Animais}

Dezoito cães foram alocados em três grupos: grupo I, composto por cães saudáveis ( $\mathrm{n}=6$ ), provenientes do canil do Hospital Veterinário, negativos na sorologia para E. canis e para Leptospira spp. (soroaglutinação microscópica), na PCR em tempo real para E. canis e para Anaplasma platys e na semi -nested PCR para Babesia canis; grupos II ( $\mathrm{n}=6)$ e III ( $\mathrm{n}=6)$, compostos por cães com história clínica compatível com erliquiose, como a ixodidiose, uveíte, esplenomegalia, febre e trombocitopenia. Além das características 
clínicas, esses cães deveriam ter sorologia (dot-ELISA, com titulação superior a 1:80) e/ou PCR em tempo real positivas para $E$. canis, e negativos na pesquisa de anticorpos anti-Leptospira spp., na PCR em tempo real para Anaplasma platys e na semi-nested PCR para Babesia canis. Os cães doentes foram selecionados da rotina clínica do Hospital Veterinário "Governador Laudo Natel", da FCAV/Unesp, Jaboticabal-SP e foram distribuídos aleatoriamente nos grupos II e III.

Os fatores de exclusão adotados foram cães com erliquiose já em tratamento, cadelas em estro, cães que apresentavam doenças pré-existentes conhecidas (endocrinopatias, doenças infecciosas, neoplasias, nefropatias, ou hepatopatias) e aqueles que receberam corticoterapia sistêmica ou tópica em até 60 dias que antecederam o diagnóstico de erliquiose. A pesquisa das coinfecções por B. canis, $A$. platys, e a leptospirose, frequentes na rotina clínica do Hospital Veterinário onde o foi estudo desenvolvido, visou a exclusão de comorbidades.

\section{Tratamento dos cães infectados}

O tratamento dos cães foi realizado unicamente com hiclato de doxiciclina (Doxitrat ${ }^{\circledR} 80 \mathrm{mg}$ ou 200mg, Agener União), em domicílio, sob os cuidados do proprietário ou responsável, durante 30 dias consecutivos, seguindo a prescrição veterinária. O grupo II recebeu aproximadamente $5 \mathrm{mg} / \mathrm{kg}$ (média de $5,58 \mathrm{mg} / \mathrm{kg} \pm 0,56$ ) via oral a cada 12 horas, e o grupo III, aproximadamente $10 \mathrm{mg} / \mathrm{kg}$ (média de 10,09 mg/ $\mathrm{kg} \pm 0,55)$ via oral a cada 12 horas. Os proprietários ou cuidadores foram instruídos para ministrar o fármaco pelo menos uma hora antes de alimentar o animal evitando, desta forma, problemas com a absorção do mesmo. A medicação necessária ao tratamento foi fornecida aos proprietários, a fim de assegurar que fosse realizado como o prescrito.

\section{Avaliação hematológica}

Coletas de sangue para a realização de hemograma foram feitas nos dias D0 (imediatamente antes do início do tratamento), D15 (decorridos 15 dias de tratamento) e D40 (avaliação final aos dez dias após o término do tratamento com hiclato de doxiciclina).

Sangue foi obtido por venopunção jugular, no volume médio de $4,0 \mathrm{~mL}$, e imediatamente depositado em tubo apropriado contendo o anticoagulante EDTA. As contagens globais de eritrócitos, leucócitos, plaquetas, determinação do volume globular e da concentração de hemoglobina foram realizadas com auxílio de um contador automático (ABC Vet ${ }^{\circledR}$, HORIBA ABX), e a leitura de esfregaços sanguíneos corados com uma solução de May-Grunwald (1 g), Giemsa (1,5 g), Wright $(0,5 \mathrm{~g})$ e Metanol (1 L), observados sob microscopia de luz, com aumento de 1000x.

“Dot-ELISA” para detecção de anticorpos anti-E. canis

Para a detecção de anticorpos anti-E. canis da classe $\operatorname{IgG}$ foi utilizado o kit Immunocomb $^{\circledR}$ Ehrlichia canis (Biogal, Israel), cujos títulos positivos (reagentes) são aqueles acima de 1:80.

\section{Diagnósticos moleculares}

As pesquisas de DNA de E. canis (PCR em tempo real), de B. canis (semi-nested PCR) e de $A$. platys (PCR em tempo real) foram realizadas de acordo com as técnicas descritas por Baneth et al. (2009), Birkenheuer, Levy e Breitschwerdt (2003) e Gaunt et al. (2010), respectivamente.

\section{Deteç̧ão de anticorpos anti-Leptospira spp.}

A sorologia para pesquisa de sorovares de Leptospira spp. foi realizada por meio da técnica de soroaglutinação microscópica (SAM). Os sorovares pesquisados foram: Andamana, Icterohaemorrhagiae, Grippotyphosa, Pomona, Panama, Autumnalis, Shermani, Copenhageni, Patoc, Castellonis, Pyrogenes, Tarassovi, Whiticombi, Australis, Hebdomadis, Butembo, Wolffi, Hardjo, 
Sentot, Canicola, Bratislava, Bataveae, Cynopteri e Javanica. Títulos menores ou iguais a 1:100 foram considerados negativos.

\section{Análise estatística}

As análises estatísticas foram executadas no programa computacional SAS versão 9.3 ("Statistical Analysis System", 2011). Para tal, foi empregada a Análise de variância de medidas repetidas para avaliar as respostas e a comparação de médias aos pares foi feita usando o teste de Tukey. O nível de significância adotado foi de 5\%.

\section{Resultados e discussão}

\section{Animais}

O grupo I foi composto por três machos e três fêmeas, com idade média de 4,5 anos $( \pm 2,3)$ e peso médio de $20,9 \mathrm{~kg}( \pm 7,1)$; o grupo II foi formado por quatro machos e duas fêmeas, com idade média de 3,9 anos $( \pm 2,1)$ e peso médio de $14,1 \mathrm{~kg}( \pm 6,7)$; já o grupo III, foi composto por quatro fêmeas e dois machos, com idade média de 4,9 anos ( \pm $1,9)$ e peso médio de $9,7 \mathrm{~kg}( \pm 3,1)$. Os cães dos grupos II e III apresentaram, ao menos, três sinais clínicos sugestivos de erliquiose: ixodidiose, febre, uveíte, hiporexia ou anorexia, esplenomegalia, emaciação, apatia, êmese e hematoquezia. Um cão no grupo II e outro no grupo III eram assintomáticos e apresentavam trombocitopenia $(125.000 / \mu \mathrm{L}$ e $44.000 / \mu \mathrm{L}$ plaquetas, respectivamente), portanto, compatíveis com a forma subclínica da doença. Os demais indivíduos possivelmente apresentavam a forma aguda da erliquiose.

Dos 12 cães doentes, quatro apresentaram a PCR em tempo real negativa, entretanto, dois eram soropositivos para E. canis, com titulação 1:80 (Grupo II) e dois, 1:320 (um cão do Grupo II e um do Grupo III). Os demais oito cães com erliquiose eram positivos tanto na sorologia quanto na detecção do DNA da E. canis.
O diagnóstico de erliquiose firmado por meio do dot-ELISA e/ou PCR em tempo real, somado a resposta terapêutica foram eficientes em restabelecer as alterações hematológicas apresentadas no tempo D0, principalmente no que tange ao número de trombócitos que, segundo Neer (1998), é um bom indicador de resposta terapêutica adequada em cães com erliquiose. Ademais, 10/12 cães tratados com hiclato de doxiciclina ganharam peso ao final do tratamento e apresentaram melhora clínica relatada pelos proprietários, como no apetite e na disposição, independente da dose do fármaco recebida. Para Harrus e Waner (2011), o diagnóstico da erliquiose monocítica canina deve se basear nos sinais clínicos apresentados e nos resultados dos testes laboratoriais, de modo que a contagem de plaquetas e a sorologia são adequadas na triagem, embora as técnicas de PCR sejam os testes confirmatórios da positividade ao agente. Os mesmos autores sugerem, ainda, que os resultados negativos à luz da PCR devem ser interpretados com cautela, tendo em vista que não se pode excluir completamente a presença de DNA da bactéria na amostra.

Alguns agentes causadores de trombocitopenia podem ser $A$. platys, devido ao parasitismo dos trombócitos (FRENCH; HARVEY, 1983), como também as Leptospira spp., por destruição imunomediada e/ou consumo de plaquetas (SYKES et al., 2011). Para tanto foi essencial incluir neste estudo, cães que fossem negativos para os demais agentes infecciosos mencionados, pois as coinfecções poderiam influenciar as análises clínicas e laboratoriais (HARRUS; WANER, 2011).

Segundo French e Harvey (1983), a reação sorológica cruzada entre E. canis e A. platys praticamente não ocorre, o que nos permite afirmar que os cães com sorologia positiva para E. canis, mas PCR negativa, não eram portadores de outros agentes causadores de trombocitopenia, ao menos os mais comuns em nossa região do estado de São Paulo. A exclusão de cães coinfectados por $B$. canis foi igualmente importante, a fim de contribuir para a uniformidade dos grupos estudados. 


\section{Parâmetros hematológicos}

Não houve diferenças entre os grupos nos tempos avaliados quanto às variáveis hemácias, hemoglobina, hematócrito e leucócitos. Entretanto, houve diferença quanto à variável plaqueta no tempo D0 entre o grupo I e os grupos II $(p<0,0001)$ e III $(\mathrm{p}<0,0001)$, mas não entre os grupos II e III neste tempo de avaliação. No tempo D15, observou-se que a média do grupo III foi menor que do grupo I $(\mathrm{p}=0,008)$ e do grupo II $(\mathrm{p}=0,0007)$, indicando a persistência da trombocitopenia, e já ausente no grupo II. No D40, não houve diferença entre os grupos ( $\mathrm{p}>0,05)$ (Figura 1; Tabela 1).

Figura 1 - Representação gráfica das contagens de hemácias (A), concentração de hemoglobina (B), hematócrito (C), contagem de leucócitos (D) e de plaquetas (E, F) dos grupos I, II e III, ao longo dos tempos D0, D15 e D40 de avaliação. * Indica diferença significativa entre os grupos, no dado tempo de avaliação $(p<0,05)$.

Hemácias

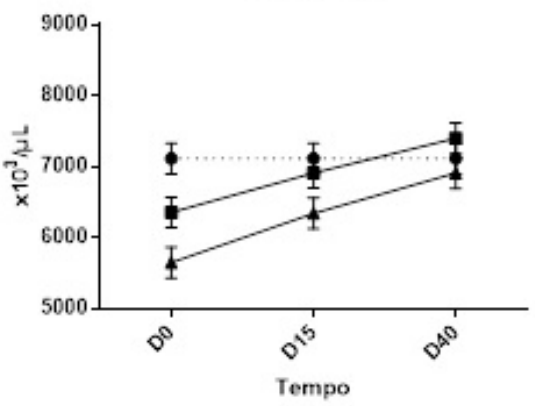

- Grupo I

- Grupoll

- Grupo III

A
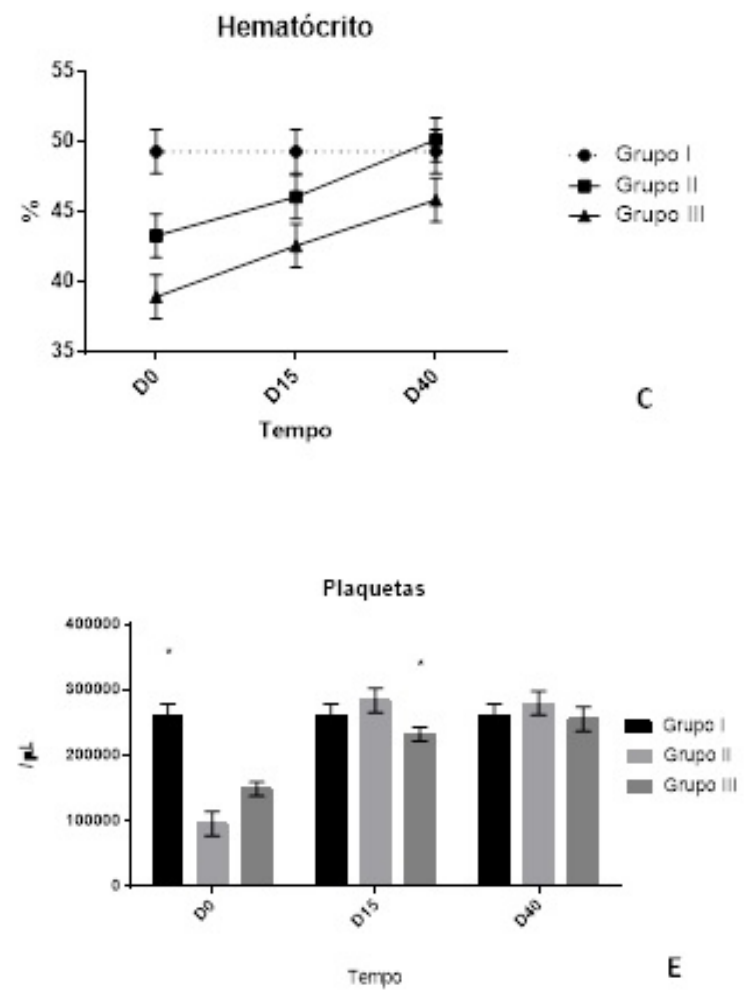

Hemoglobina

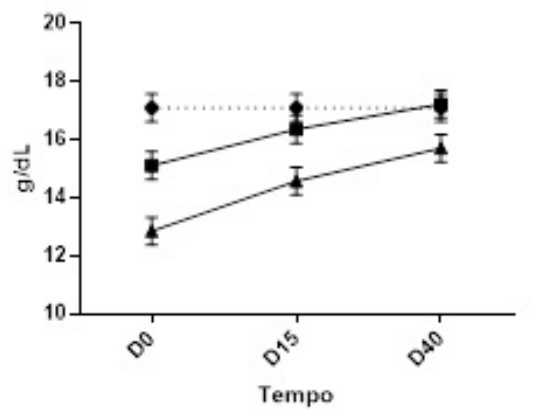

- Grupo I

- Grupo I

屯 Grupo II

B
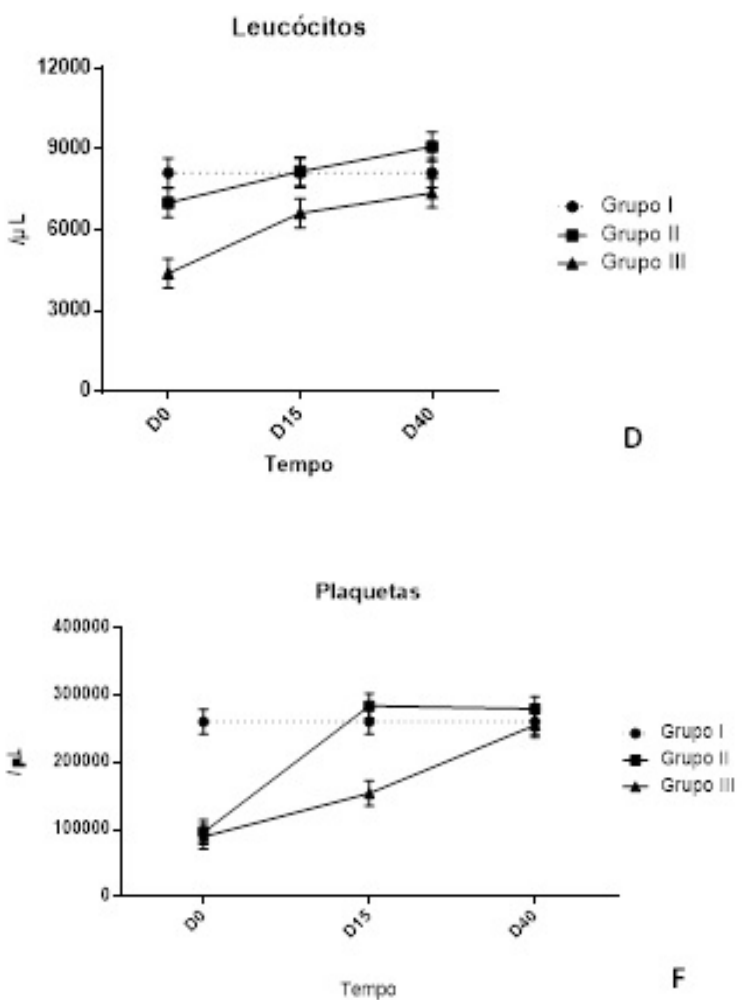

Fonte: Autores. 
Tabela 1 - Média \pm erro padrão da média das contagens de hemácias, concentração de hemoglobina, hematócrito, contagem de leucócitos e de plaquetas dos grupos I, II e III, nos tempos experimentais D0, D15 e D40.

\begin{tabular}{|c|c|c|c|c|}
\hline \multirow[t]{2}{*}{ Parâmetro } & Grupo & D0 & D15 & D40 \\
\hline & GI & $7.115 \pm 218,3$ & $7.115 \pm 218,3$ & $7.115 \pm 218,3$ \\
\hline \multirow{3}{*}{$\begin{array}{l}\text { Hemácias } \\
\left(\times 10^{3} / \mu L\right)\end{array}$} & GII & $6.355 \pm 218,3$ & $6.913,33 \pm 218,3$ & $7.401,67 \pm 218,3$ \\
\hline & GIII & $5.648,33 \pm 218,3$ & $6.343,33 \pm 218,3$ & $6.910 \pm 218,3$ \\
\hline & GI & $17,10 \pm 0,48$ & $17,10 \pm 0,48$ & $17,10 \pm 0,48$ \\
\hline \multirow{3}{*}{$\begin{array}{c}\text { Hemoglobina } \\
\text { (g/dL) }\end{array}$} & GII & $15,11 \pm 0,48$ & $16,36 \pm 0,48$ & $17,23 \pm 0,48$ \\
\hline & GIII & $12,85 \pm 0,48$ & $14,58 \pm 0,48$ & $15,71 \pm 0,48$ \\
\hline & GI & $49,33 \pm 1,55$ & $49,33 \pm 1,55$ & $49,33 \pm 1,55$ \\
\hline \multirow[t]{3}{*}{$\begin{array}{c}\text { Hematócrito } \\
(\%)\end{array}$} & GII & $43,33 \pm 1,55$ & $46,10 \pm 1,55$ & $50,18 \pm 1,55$ \\
\hline & GIII & $38,98 \pm 1,55$ & $42,61 \pm 1,55$ & $45,88 \pm 1,55$ \\
\hline & GI & $8.133,33 \pm 538,6$ & $8.133,33 \pm 538,6$ & $8.133,33 \pm 538,6$ \\
\hline \multirow[t]{3}{*}{$\begin{array}{l}\text { Leucócitos } \\
\qquad(/ \mu \mathrm{L})\end{array}$} & GII & $7.016,67 \pm 538,6$ & $8.183,33 \pm 538,6$ & $9.100 \pm 538,6$ \\
\hline & GIII & $4.400 \pm 538,6$ & $6.633,33 \pm 538,6$ & $7.383,33 \pm 538,6$ \\
\hline & GI & $260.833,33 \pm 18.487,5^{\mathrm{Aa}}$ & $260.833,33 \pm 18.487,5^{\mathrm{Aa}}$ & $260.833,33 \pm 18.487,5^{\text {Aa }}$ \\
\hline \multirow[t]{2}{*}{$\begin{array}{l}\text { Plaquetas } \\
\qquad(/ \mu \mathrm{L})\end{array}$} & GII & $96.000 \pm 18.487,5^{\mathrm{Bb}}$ & $284.333,33 \pm 18.487,5^{\mathrm{Aa}}$ & $280.166,67 \pm 18.487,5^{\text {Аа }}$ \\
\hline & GIII & $89.333,33 \pm 18.487,5^{\mathrm{Bb}}$ & $154.000 \pm 18.487,5^{\mathrm{Bb}}$ & $255.666,67 \pm 18.487,5^{\text {Аа }}$ \\
\hline
\end{tabular}

GI: grupo I; GII: grupo II (5 mg/kg de hiclato de doxiciclina); GIII: grupo III (10 mg/kg de hiclato de doxiciclina); D0: dia zero de avaliação; D15: dia quinze de avaliação; D40: dia quarenta de avaliação. Letras maiúsculas diferentes na mesma coluna indicam diferença significativa (Teste de Tukey; $p<0,05$ ). Letras minúsculas diferentes na mesma linha indicam diferença significativa (Teste de Tukey; $\mathrm{p}<0,05$ ).

Fonte: Autores.

Trombocitopenia foi o primeiro fator de inclusão dos animais neste estudo. Portanto, era esperado que houvesse diferença significativa entre o grupo I e os grupos II e III no tempo D0. Neste âmbito, Munhoz et al. (2009) identificaram trombocitopenia em cães infectados experimentalmente por $E$. canis (Amostra Jaboticabal), a partir do sexto dia de infecção, apresentando seu pico aos 18 dias de infecção e corrigida aos 76 dias pós-infecção (que correspondiam a 25 dias após o fim do tratamento com $5 \mathrm{mg} / \mathrm{kg}$ de hiclato de doxiciclina, a cada 12 horas por 21 dias). O nosso estudo foi desenvolvido na mesma região do Estado de São Paulo que o trabalho dos pesquisadores anteriormente citados, portanto, 
as mesmas variações na contagem de plaquetas eram esperadas, por se tratar, possivelmente, de infecção pela mesma amostra de E. canis, embora por metodologia diferentes: infecção experimental no estudo de Munhoz et al. (2009) e infecção de ocorrência natural no estudo em tela.

As diferenças observadas entre o grupo III e os grupos I e II no tempo D15 de avaliação mostram que os cães do grupo II, que receberam $5,0 \mathrm{mg} /$ $\mathrm{kg}$ de hiclato de doxiciclina, via oral, a cada 12 horas, apresentavam o valor médio de trombócitos no intervalo de referência para a espécie canina já aos 15 dias de avaliação, enquanto que os cães do grupo III (que receberam $10 \mathrm{mg} / \mathrm{kg}$ de hiclato de doxiciclina, via oral, a cada 12 horas, por 30 dias), demonstraram aumento da contagem de plaquetas aos 40 dias de avaliação. Segundo dados da literatura estrangeira, a trombocitopenia deve ser eliminada em aproximadamente 14 dias de tratamento com doxiciclina (IGBAL; RIKIHISA, 1994), semelhante ao observado no grupo II do estudo em tela. Mormente, a não significância entre os grupos em D40 demonstra a eficácia do fármaco no aumento progressivo da contagem das plaquetas, apesar das diferentes doses empregadas para os tratamentos dos cães com E. canis.

Todavia, individualmente, em dois cães do grupo III registrou-se persistência da trombocitopenia no D40, motivando a realização da avaliação medular por meio da punção de medula óssea, a fim de se excluir a hipoplasia ou aplasia de medula óssea, eventos frequentes nos cães com erliquiose (HARRUS; WANER; BARK, 1997). Nos dois casos, o mielograma revelou ausência de alterações quanto aos precursores mielóides, o que sugeria a ocorrência de desordem imunomediada. Os cães foram submetidos a imunossupressão com prednisona (2 $\mathrm{mg} / \mathrm{kg}$ via oral a cada 12 horas por 30 dias), com controle do quadro em um deles. No outro caso, a resposta foi pobre, o que motivou a introdução de ciclosporina ( $5 \mathrm{mg} / \mathrm{kg}$ via oral a cada 24 horas) por 30 dias, sem melhora. O paciente foi, então, submetido à esplenectomia, com correção do problema.
$\mathrm{Na}$ trombocitopenia imunomediada, anticorpos se ligam à superfície de trombócitos, em geral os da classe $\mathrm{IgG}$, e promovem a remoção destes por meio da ação dos macrófagos do sistema retículoendoplasmático (LEWIS; MEYERS, 1996). A destruição imunomediada de plaquetas ocorre secundariamente a diversas condições, sendo que as doenças infecciosas corresponderam a $31 \%$ das causas de trombocitopenia imunomediada secundária em um estudo conduzido por Dircks, Schuberth e Mischke (2009). Neste mesmo estudo, a erliquiose figurou como causa de trombocitopenia imunomediada em seis dos 86 cães avaliados. Da mesma forma, a ocorrência de trombocitopenia imunomediada em dois cães do grupo III deve ser avaliada com cuidado, não podendo ser atribuída ao tratamento da erliquiose com a dose de $10 \mathrm{mg} / \mathrm{kg}$ do fármaco, pois esta consequência já foi observada com outras posologias em nossa rotina clínica. Sendo assim, este evento requer investigação adicional.

Em um estudo recente, Villaescusa et al. (2015) avaliaram os efeitos da doxiciclina sobre os parâmetros hematológicos de cães com erliquiose monocítica espontânea tratados com $10 \mathrm{mg} / \mathrm{kg}$ a cada 24 horas por 28 dias, e acompanhados por um período de seis meses. Para fins comparativos, um grupo de cães saudáveis foi submetido ao mesmo tratamento. Houve aumento progressivo da contagem de hemácias e concentração de hemoglobina no grupo de cães com erliquiose, mas não no grupo controle, e isto foi atribuído ao efeito antimicrobiano do fármaco. Adicionalmente houve aumento da contagem de plaquetas em ambos os grupos, o que os permitiu sugerir que a doxiciclina pode exercer algum efeito sobre a produção de plaquetas sem, contudo, fornecer maiores detalhes. Por fim, Villaescusa et al. (2015) consideraram uma limitação do estudo a ausência de um grupo placebo, assim como a possibilidade de os cães selecionados apresentarem comorbidades adjacentes, apesar das exclusões sorológica e molecular de Ehrlichia spp., Anaplasma spp., Neorickettsia spp. e Leishmania spp.. No estudo em tela, reconhecemos que seria 
interessante a inclusão de grupos de cães não doentes, que recebessem as mesmas doses de 5,0 e de $10 \mathrm{mg} /$ $\mathrm{kg}$ de hiclato de doxiciclina tal como nos grupos II e III, a fim de excluir a possibilidade de o aumento de trombócitos observado nos cães doentes ser ou não devido ao efeito do fármaco.

\section{Conclusão}

Os resultados deste estudo, nos moldes em que foi desenvolvido, permitem concluir que ambos os tratamentos adotados promoveram aumento progressivo da contagem de plaquetas em cães naturalmente infectados por E. canis, restabelecendo os valores de referência para a espécie.

\section{Agradecimentos}

Os autores agradecem a Fundação de Amparo a Pesquisa do Estado de São Paulo (FAPESP) pelo bolsa de doutorado concedida (Processo 2012/10207-9) e ao Laboratório de Patologia Clínica do Hospital Veterinário "Governador Laudo Natel", da FCAV/Unesp, Jaboticabal-SP pela condução das análises hematológicas.

\section{Referências}

BANETH, G.; HARRUS, S.; OHNONA, F. S.; SCHLESINGER, Y. Longitudinal quantification of Ehrlichia canis in experimental infection with comparison to natural infection. Veterinary Microbiology, Amsterdam, v. 136, p. 321-325, 2009.

BIRKENHEUER, A. J.; LEVY, M. G.; BREITSCHWERDT, E. B. Development and evaluation of a seminested PCR for detection and differentiation of Babesia gibsoni (Asian Genotype) and B. canis DNA in Canine Blood Samples. Journal of Clinical Microbiology, Washington, v. 41, n.9, p. $4172-4177,2003$.

BULLA, C.; KIOMI TAKAHIRA, R.; PESSOA ARAÚJO, J. JUNIUOR.; APARECIDA TRINCA, L.; SOUZA LOPES, R.; WIEDMEYER, C. E. The relationship between the degree of thrombocytopenia and infection with Ehrlichia canis in an endemic area. Veterinary Research, Les Ulis, v. 35, n. 1, p. $141-146,2004$.
DAGNONE, A. S.; SOUZA, A. I.; ANDRÉ, M. R.; MACHADO, R. Z. Molecular diagnosis of Anaplasmataceae organisms in dogs with clinical and microscopical signs of ehrlichiosis. Revista Brasileira de Parasitologia Veterinária, São Paulo, v. 18, n. 4 , p. $20-25,2009$.

DIRCKS, B. H.; SCHUBERTH, H. J.; MISCHKE, R. M. Underlying diseases and clinicopathologic variables of thrombocytopenic dogs with and without platelet-bound antibodies detected by use of a flow cytometric assay: 83 cases (2004-2006). Journal of the American Veterinary Medical Association, Schaumburg, v. 235, n. 8, p. 960966, 2009.

FRENCH, T. W.; HARVEY, J. W. Serologic diagnosis of infectious cyclic thrombocytopenia in dogs using an indirect fluorescent antibody test. American Journal of Veterinary Research, Chicago, v. 44, p. 2407-2411, 1983.

GAUNT, S. D.; BEALL, M. J.; STILLMAN, B. A.; LORENTZEN, L.; DINIZ, P. P. V. P.; CHANDRASHEKAR, R.; BREITSCHWERDT, E. B. Experimental infection and co-infection of dogs with Anaplasma platys and Ehrlichia canis: hematologic, serologic and molecular findings. Parasites \& Vectors, Keele, v. 3, n. 33, p. 2-10, 2010 .

HARRUS, S.; WANER, T. Diagnosis of canine monocytotropic ehrlichiosis (Ehrlichia canis): An overview. The Veterinary Journal, London, v. 187, n. 1, p. 292-296, 2011.

HARRUS, S.; WANER, T.; BARK, H. Canine monocytic ehrlichiosis: an update. Compendium Continuing Education for the Practicing for Veterinarians, Columbus, v. 19, p. 431-444, 1997.

IGBAL, Z.; RIKIHISA, Y. Reisolation of Ehrlichia canis from blood and tissues of dogs after doxycycline treatment. Journal of Clinical Microbiology, Washington, v. 32, p. 1644-1649, 1994.

LAPPIN, M. R. Erliquiose canina. In: NELSON, R.; COUTO, G. Medicina interna de pequenos animais. 3. ed. Rio de Janeiro: Elsevier, 2006. p. $1229-1232$. 
LEWIS, D. C.; MEYERS, K. M. Canine idiopathic thrombocytopenic purpura. Journal of Veterinary Internal Medicine, Lawrence, v. 10, p. 207-218, 1996.

MOREIRA, S. M.; BASTOS, C. V.; ARAÚJO, R. B.; SANTOS, M.; PASSOS, L. M. F. Retrospective study (1998-2001) on canine ehrlichiosis in Belo Horizonte, MG, Brazil. Arquivo Brasileiro de Medicina Veterinária e Zootecnia, Belo Horizonte, v. 55, n. 2, p. 141-147, 2003.

MUNHOZ, T. D.; FARIA, J. L. M.; VARGASHÉRNANDEZ, G.; FAGLIARI, J. J.; SANTANA, A. E.; MACHADO, R. Z.; TINUCCI-COSTA, M. Experimental Ehrlichia canis infection changes acutephase proteins. Revista Brasileira de Parasitologia Veterinária, São Paulo, n. 21, p. 206-212, 2012.

MUNHOZ, T. D.; FARIA, J. L. M.; VARGASHERNANDES, G.; JOÃO, C. F.; PEREIRA, W. A. B.; ANDRÉ, M. R.; MACHADO, R. Z.; TINUCCICOSTA, M. Mensuração da proteína C-reativa na infecção experimental por Ehrlichia canis (Amostra Jaboticabal) e após o tratamento com cloridrato de doxiciclina em cães. Veterinária Notícias, Uberlândia, v. 15, n. 2, p. 65-79, 2009.

NEER, T. M. Canine monocytic and granulocytic ehrlichiosis. In: GREENE, C. E. (Ed.). Infectious diseases of the dog and cat. $2^{\text {nd }}$ ed. Philadelphia: W. B. Saunders, 1998. p. 139-147.

NEER, T. M.; BREITSCHWERDT, E. B.; GREENE, R. T.; LAPPIN, M. R. Consensus statement on ehrlichial disease of small animals from the infectious disease study group of the ACVIM. Journal of Veterinary Internal Medicine, Lawrence, v. 16, p. 309315, 2002.

NEER, T. M.; HARRUS, S. Canine monocytotropic ehrlichiosis and neorickettiosis (E. canis, $E$. chaffeensis, E. ruminatium, $N$. sennetsu, and $N$. risticii Infections). In: . GREENE, C. Infectious diseases of the dog and cat. Philadelphia: Saunders, 2006. p. $203-216$.

SPINOSA, E. S. Antibióticos: tetraciclinas, cloranfenicol e análogos. In: _. . SPINOSA, E. S.; GORNIÁK, S. L.; BERNARDI, M. M. Farmacologia aplicada à medicina veterinária. 3.ed. Rio de Janeiro: Guanabara Koogan, 2002. p. 420-424.
SYKES, J. E.; HARTMANN, K.; LUNN, K. F.; MOORE, G. E.; STODDARD, R. A.; GOLDSTEIN, R. E. 2010 ACVIM Small Animal Consensus Statement on Leptospirosis: Diagnosis, Epidemiology, Treatment, and Prevention. Journal of Veterinary Internal Medicine, Lawrence, v. 25, p. $1-13,2011$.

TROY, G. C., FORRESTER, S. D. Canine ehrlichiosis. In: GREENE, C. E. Infectious diseases of the dog and cat. Philadelphia: Saunders, 1990. p. 404-414.

VILLAESCUSA, A.; GARCÍA-SANCHO, M.; RODRÍGUEZ-FRANCO, F.; TESOURO, M.; SAINZ, Á. Effects of doxycycline on haematology, blood chemistry and peripheral blood lymphocyte subsets of healthy dogs and dogs naturally infected with Ehrlichia canis. The Veterinary Journal, London, v. 204, p. 263-268, 2015. 
